\title{
Steroid signalling in human ovarian surface epithelial cells: the response to interleukin-1 $\alpha$ determined by microarray analysis
}

\author{
M T Rae, D Niven, A Ross ${ }^{1}$, T Forster $^{1}$, R Lathe ${ }^{2}$, \\ H O D Critchley, P Ghazal ${ }^{1}$ and S G Hillier
}

\author{
University of Edinburgh Centre for Reproductive Biology, The Chancellor's Building, 49 Little France Crescent, Edinburgh EH16 4SB, UK \\ ${ }^{1}$ Scottish Centre for Genomic Technology and Informatics (GTI), The Chancellor's Building, 49 Little France Crescent, Edinburgh EH16 4SB, UK \\ ${ }^{2}$ Pieta Research, PO Box 27069, Edinburgh EH10 5YW, UK \\ (Requests for offprints should be addressed to M T Rae: mrae1@staffmail.ed.ac.uk)
}

\begin{abstract}
The human ovarian surface epithelium (HOSE) is a common site of gynaecological disease including endometriosis and ovarian cancer, probably due to serial injury-repair events associated with successive ovulations. To comprehend the importance of steroid signalling in the regulation of the HOSE, we used a custom microarray to catalogue the expression of over 250 genes involved in the synthesis and reception of steroid hormones, sterols and retinoids. The array included a subset of non-steroidogenic genes commonly involved in pro-/anti-inflammatory signalling. HOSE cells donated by five patients undergoing surgery for non-malignant gynaecological conditions were cultured for $48 \mathrm{~h}$ in the presence and absence of $500 \mathrm{pg} /$ $\mathrm{ml}$ interleukin-1 $\alpha$ (IL-1 $\alpha)$. Total RNA was reversetranscribed into biotin-labelled cDNA, which was hybridised to the array and visualised by gold-particle resonance light scattering and charge-coupled device (CCD) camera detection. Results for selected genes were verified by quantitative reverse-transcription PCR. In five out of five cases, untreated HOSE cells expressed genes encoding enzymes required for de novo biosynthesis of cholesterol from acetate and subsequent formation of C21-pregnane and C19-androstane steroids. Consistent with the inability
\end{abstract}

of HOSE cells to synthesise glucocorticoids, oestrogens or $5 \alpha$-reduced androgens de novo, CYP21, CYP19 and $5 \alpha$-reductase were not detected. The only steroidogenic gene significantly up-regulated by IL- $1 \alpha$ was $11 \beta$ hydroxysteroid dehydrogenase type 1 (11ßHSD1). Other cytokine-induced genes were IL-6, IL- 8 , nuclear factor $\kappa \mathrm{B}$ (NFKB) inhibitor $\alpha$, metallothionein-IIA and lysyl oxidase: inflammation-associated genes that respond to glucocorticoids. The only steroidogenic gene significantly suppressed by IL- $1 \alpha$ was $3 \beta$ HSD 1 . Other genes suppressed by IL $-1 \alpha$ were aldehyde dehydrogenase (ALDH) 1, ALDH 10, gonadotrophin hormone-releasing hormone receptor, peroxisome proliferation-activated receptor-binding protein (PPAR-bp) and nuclear receptor subfamily 2 group $\mathrm{F}$ member 2. These results define a steroidogenic phenotype of cultured HOSE cells and provide a limited expression profile for genes with associated signalling functions. IL-1 $\alpha$ co-ordinately induces $11 \beta$ HSD 1 and a panel of glucocorticoid-regulated, inflammation-associated genes in HOSE cells, providing further evidence that cortisol generated by $11 \beta \mathrm{HSD} 1$ could participate in the local resolution of inflammation associated with ovulation.

Journal of Endocrinology (2004) 183, 19-28

\section{Introduction}

The steroid-secretory function of the ovaries is well recognised but the capacity of the human ovarian surface epithelium (HOSE) to synthesise, metabolise and respond to steroids remains obscure. The probable importance of steroid signalling in the HOSE relates to the tendency of this cellular layer to undergo neoplastic transformation and produce fatal tumours. Ovarian cancers represent approximately $4 \%$ of all gynaecological cancers and are the fifth highest cause of death from cancer among women. Over $90 \%$ of ovarian cancers in women are believed to originate in the HOSE. Many such cancers are steroid responsive and one of the major negative-risk factors is anovulation associated with steroidal oral contraceptive usage. HOSE cells are believed to be steroid responsive on the basis that exposure to ovarian steroids in vitro affects HOSE cell proliferation (Karlan et al. 1995) and that they express nuclear hormone receptors, including oestrogen receptor (ER; Hiller et al. 1998, Lau et al. 1999, Li et al. 2003), androgen receptor (AR; Lau et al. 1999, Edmondson et al. 2002) and progesterone receptor (PR; Karlan et al. 1995, Lau et al. 1999, Li et al. 2003), which presumably mediate these effects. Involvement of HOSE cells in steroid biosynthesis is less certain. However, definitive evidence for steroid metabolism comes from the recent discovery 
that cultured HOSE cells express the glucocorticoidmetabolising enzyme 11 $\beta$-hydroxysteroid dehydrogenase type 1 (11ßHSD1), which is up-regulated by exposure to interleukin-1 $\alpha$ (IL-1 $\alpha$ ) (Yong et al. 2002, Rae et al. 2004). Pro-inflammatory cytokines such as IL-1 $\alpha$ are increasingly produced by follicular cells at the time of ovulation, therefore up-regulation of $11 \beta \mathrm{HSD} 1$ could be a mechanism for increasing local metabolism of substrate cortisone to cortisol and promoting anti-inflammatory glucocorticoid action at the ovarian surface (Hillier \& Tetsuka 1998).

To define the steroidogenic signature of the HOSE we developed a custom gene microarray probing the enzymes that catalyse the complete steroidogenic pathway, from acetate through cholesterol to the principal hormonal steroids and their metabolites. The gene-set also contains nuclear receptors of known and unknown functions and a limited selection of genes encoding pro-/antiinflammatory mediators. Here we apply this microarray to analyse RNA from primary HOSE cell cultures, with and without prior exposure of cells to IL-1 $\alpha$. The results define a steroidogenic phenotype of normal HOSE cells and identify a panel of associated HOSE genes with likely roles in normal and abnormal ovarian function. Several such genes are glucocorticoid responsive and are likely to be involved in the injury-repair process associated with ovulation.

\section{Materials and Methods}

\section{Patients}

HOSE cells were obtained (with informed consent after local ethics committee approval) from normal ovaries of eight premenopausal women undergoing surgery for nonmalignant gynaecological conditions. Cells were collected at laparotomy by gentle scraping of the ovarian surface with a sterile wooden spatula, which was then rinsed into sterile, pre-warmed, culture medium (see below). Cells were collected as near as practicable to the beginning of the surgical procedure to avoid any contamination with blood cells. Collections were then examined by phasecontrast microscopy to verify that a representative biopsy of the HOSE had been recovered.

\section{Production of HOSE cell monolayers}

All cultures were produced and handled in an identical manner, using reagents made from a common stock. The tissue culture reagents were obtained from Gibco and Sigma. HOSE scrapings were cultured in donor calf serum-precoated flasks $\left(75 \mathrm{~cm}^{2}\right.$; Corning Inc, Glass Works, Corning, NY, USA). Culture medium (HOSE 1) consisted of Medium199:MCDB105 (1:1 v/v) supplemented with fetal calf serum $(15 \% \mathrm{v} / \mathrm{v})$, streptomycin
$(50 \mu \mathrm{g} / \mathrm{ml})$, penicillin $(50 \mathrm{IU} / \mathrm{ml})$ and L-glutamine (2 mM) (Yong et al. 2002). Cells were incubated at $37^{\circ} \mathrm{C}$ in a humidified incubator under an atmosphere of $95 \%$ air-5\% $\mathrm{CO}_{2}$ for 21 days, with medium renewed every 7 days. HOSE cell monolayers were routinely examined by phase-contrast microscopy for contaminating fibroblasts. Cell purity was checked in selected cases by immunocytochemical staining for cytokeratin 5, 6, 8 and 17 (Auersperg et al. 2001) using a commercially available monoclonal anti-human cytokeratin antibody (Dako, Ely, Cambridgeshire, UK), which confirmed that the monolayers comprised pure epithelial cells (data not shown).

\section{Experimental treatment of cultured HOSE cells}

Each set of experiments was applied identically to cells donated by five different patients. HOSE cell monolayers (21 days old) were dispersed by treatment with trypsinEDTA in Hanks' balanced salt solution $(0.05 \% \mathrm{w} / \mathrm{v}$ trypsin, $0.5 \mathrm{mM}$ EDTA, Invitrogen) for exactly $5 \mathrm{~min}$ at $37^{\circ} \mathrm{C}$. Cells were collected by centrifugation for $5 \mathrm{~min}$ at $800 \mathrm{~g}$, and the pellet was washed once and re-susupended in fresh HOSE 1 medium. Cell counts were done with a haemocytometer using trypan blue (Sigma) dye-exclusion to determine viability (75-90\%). The cell suspension was adjusted to a concentration of 100000 cells $/ \mathrm{ml}$ with HOSE 1 medium and $15 \mathrm{ml}$ portions dispersed into fresh $75 \mathrm{~cm}^{2}$ culture flasks, which were incubated for $24 \mathrm{~h}$ at $37^{\circ} \mathrm{C}$ to allow cell attachment. The medium was then replaced with serum-depleted medium (HOSE 2) containing $0 \cdot 01 \%$ BSA $(\mathrm{w} / \mathrm{v})$ and incubation continued for a further $24 \mathrm{~h}$. Spent medium was then replaced with fresh HOSE 2 containing no addition (control) or $500 \mathrm{pg} / \mathrm{ml}$ recombinant human IL-1 $\alpha$ (R\&D Systems Europe Ltd, Abingdon, Oxon, UK), with incubation for $48 \mathrm{~h}$ at $37^{\circ} \mathrm{C}$. These conditions have previously been shown to be optimal for inducing $11 \beta \mathrm{HSD}$ enzymatic activity in cultured HOSE cells (Yong et al. 2002, Rae et al. 2004). Total RNA was then extracted from the cell monolayers as described below. Additional experiments to establish the effects of cortisol on IL-1 $\alpha$ induced lysyl oxidase (LOX) gene expression were performed as previously described (Rae et al. 2004), using primary HOSE cell cultures donated by a further three patients.

\section{RNA extraction and quality analysis}

RNA was extracted using RNeasy minispin columns (Qiagen) as per manufacturer's protocols, in combination with on-column DNase-I treatment (Qiagen). Aliquots $(1 \mu \mathrm{l})$ of purified RNA were removed for quantification and quality assessment of total RNA using the Agilent 2100 Bioanalyser system in combination with RNA $_{6000}$ nano chips (Agilent Technologies, Cheshire, UK). Only RNA that displayed intact $18 \mathrm{~S}$ and $28 \mathrm{~S}$ peaks 
was reverse transcribed (RT) to cDNA for real-time PCR analysis. This quality-control step was included for each experimental run to avoid generation of false-negative results due to RNA degradation before and during extraction steps, and also as a quantification method to ensure equal amounts of RNA were transcribed in each RT reaction.

\section{EUROSTERONE microarray fabrication}

The gene sets used on the microarray were chosen by the European Commission funded EUROSTERONE consortium (Hillier 2003), comprising 256 genes involved in steroid signalling, including enzymes of the major biochemical pathways of cholesterol and steroid hormone biosynthesis, nuclear hormone receptors and a subset of associated genes implicated in pro-/anti-inflammatory signalling. Fifty-mer oligonucleotides specific for each gene were selected in-house and synthesised by MWG (Milton Keynes, UK). Oligonucleotides were dissolved in $75 \mathrm{mM}$ sodium-phosphate buffer containing 0.005\% (w/v) SDS. Plates of oligonucleotide solutions were prepared using a Roboamp4200 (MWG) and spotted in triplicate on to Corning GAPS II slides $(25 \times 27 \mathrm{~mm}$ bar-coded, lot. 34802000B, Corning, Netherlands) using a MG2 array spotter (Biorobotics, Cambridgeshire, UK) in conjunction with $200 \mu \mathrm{m}$ solid pins, producing a spot diameter of 310-330 $\mu \mathrm{m}$, under temperature and humidity conditions of $16-18{ }^{\circ} \mathrm{C}$ and $35-45 \%$ respectively. After spotting was complete and slides had dried, oligonucleotide spots were covalently linked to the aminosilane slide coating by exposure to u.v. light $(250 \mathrm{~mJ})$ (GS Genelinker UV chamber, BioRad). The arrays were stored desiccated at room temperature for use within 2 weeks of preparation to avoid any potential decline in sensitivity.

\section{Preparation of labelled $\mathrm{cDNA}$ and hybridisation}

Biotin-d-11-UTP (Roche) was incorporated into cDNA during reverse transciption using a Labelstar kit as per manufacturer's instructions (Qiagen); in each case using exactly $6 \mu \mathrm{g}$ (as measured by an Agilent Bioanalyser, and confirmed by spectrophotometry) Dnase-treated RNA. The protocol used in the Labelstar kit can be used with 0.5-50 $\mu \mathrm{g}$ RNA template. An advantage of this method is the endogenous exonuclease activity of the reverse transcriptase enzyme preparation, which avoids unnecessary lysis of RNA template by harsh reagent conditions. cDNA was purified from reaction mixtures by silica-gel binding columns (Qiagen). Hybridisation of exactly $50 \%$ of the cDNA produced (equivalent to $3 \mu \mathrm{g}$ RNA template) was carried out for $18 \mathrm{~h}$ at $42{ }^{\circ} \mathrm{C}$ in a humidified hybridisation oven using reagents from a Qiagen HiLight single-colour (gold particles) array detection hybridisation kit. The hybridisation chambers used were single-slide, rubbersealed units (Camlab, Cambridge, UK). Post-hybridisation washes and detection by addition of anti-biotin serum labelled with colloidal gold was performed as described by the manufacturer's (Qiagen) protocols, except that solution removal was done by centrifugation and the volume of each kit component was adjusted for use with the smaller print area of the array used in this study. In pilot studies, we found that these methods of hybridisation and subsequent detection by gold-particle resonance-light scattering and charge-coupled device (CCD) camera detection were $>10$-fold more sensitive than conventional Cye-3/5 labelling and detection strategies as regards signal intensity and amount of template RNA required. We ascertained using the resonance-light scattering system that negligible differences in results occurred using between 1 and $5 \mu \mathrm{g}$ RNA-templated cDNA, and greater amounts of RNA template were found to be deleterious to array detection. A separate chip was used to analyse each sample (i.e. control and treated samples from each patient were run on separate chips), thus avoiding the need for dye/metal particle-swap experiments.

\section{Scanning and analysis}

Each array was scanned eight times at increasing CCD camera exposure times (there is no photo-bleaching effect with this type of detection). Bitmap scan files were then quantified using Quantarray (Perkin-Elmer, Chalfont, Bucks, UK), using fixed-circle detection parameters, and the resulting comma separated value (CSV) format data exported to Microsoft Excel for manipulation and analysis. Scatter-plots of each scanner setting were created and used to identify which CCD setting gave the optimal dataset for each array, as previously described (Forster et al. 2003). Optimal scanner data for each array were then normalised to the mean 75th percentile of total array signal (global normalisation, as previously described (Forster et al. 2003). As a data-quality filter, the sensitivity threshold for each array was taken as the 80th percentile of 15 negativecontrol genes. Values below this number were removed from the dataset for that particular array. In rare cases where genes were either newly induced or completely suppressed by treatment, sub-sensitivity threshold values were analysed to permit statistical analysis of treatment effects. Data were logarithmically transformed to base 2, then further analysed with a $t$-test for dependent samples (paired, two-way $t$-test) on a per-gene basis, utilising the statistical dependence between the treated and untreated samples per patient to best effect. Statistical sample size was limited by patient numbers, therefore consistent with our hypothesis-driven approach, analysis was limited to an 'interest-filter' approach whereby genes were selected on their significance levels (cut-off for statistical significance was set at alpha $=0 \cdot 05$ ). Permutation testing was used to confirm or refute these analyses, and a subset of 


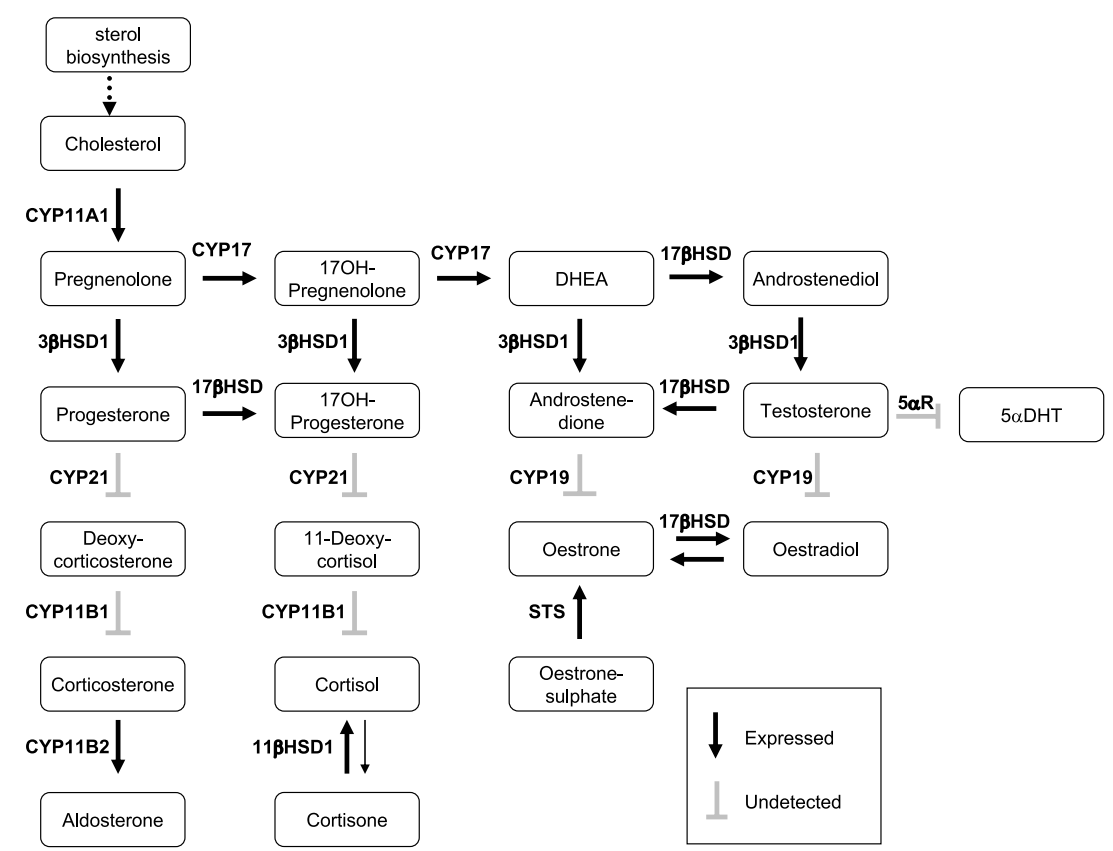

Figure 1 Steroidogenic signature of cultured HOSE cells. Schematic summary of potential for de novo steroid synthesis and metabolism under basal conditions of culture, based upon EUROSTERONE custom microarray analysis.

genes significantly modulated by treatment were further validated by real-time PCR analysis (below).

\section{Real-time PCR analysis}

DNase-treated (Qiagen) RNA (200 ng) was reverse transcribed (RT; random hexamer kit; Applied Biosystems, Warrington, UK) and $2 \mu \mathrm{l}$ of the resultant RT-mix analysed. cDNA was analysed in a $25 \mu \mathrm{l}$ final assay volume containing $300 \mathrm{nM}$ primers and $200 \mathrm{nM}$ TaqMan hybridisation probe (Biosource UK Ltd, Essex, UK). Primers and probes were designed using Primer-Express software (Perkin-Elmer, Boston, MA, USA) and validated prior to use (11ßHSD1 primers and probe; Yong et al. 2002), or were purchased pre-validated from Applied Biosystems (Assay-on-Demand systems). Target mRNA was quantified in relation to $18 \mathrm{~S}$ ribosomal RNA abundance in each sample. Negative controls consisted of RT-negative (RNA template with no reverse transcriptase enzyme), and $\mathrm{RT}-\mathrm{H}_{2} \mathrm{O}$ (water in place of RNA template) samples generated at the time of reverse transcription of samples, plus a TaqMan-reaction negative control where cDNA was replaced with water. In the case of the experiments examining the effects of glucocorticoids on IL1 $\alpha$ modulated genes (LOX), this was performed as previously described for a range of other genes in HOSE cells (Rae et al. 2004), using a $48 \mathrm{~h}$ treatment-incubation time in all cases. Data were logarithmically transformed to base 10 and then analysed by ANOVA with Student's $t$-test to determine specific treatment effects.

\section{Results}

Untreated HOSE cells from all five patients expressed genes encoding many of the enzymes involved in classic pathways of steroid biosynthesis metabolism and action. The full normalised signature dataset is provided as a supplementary table to the online version of Journal of Endocrinology (see http://joe.endocrinology-journals. org/content/vol183/issue1/). In addition, original data as well as selected data not shown in the manuscript are available (accession no. GXE-00021), in the MIAME compliant GTI expression pathway database, GPXdb(http://www.gti.ed.ac.uk).

\section{Steroid biosynthesis}

All the enzymes required for de novo formation of C21pregnane and C19-androstane steroids from acetate via cholesterol were significantly detected. However, CYP21 and CYP19 were not expressed at levels above the sensitivity threshold of the array, suggesting that HOSE cells are unlikely to be able to undertake de novo synthesis of biologically active glucocorticoids or oestrogens (Fig. 1). 


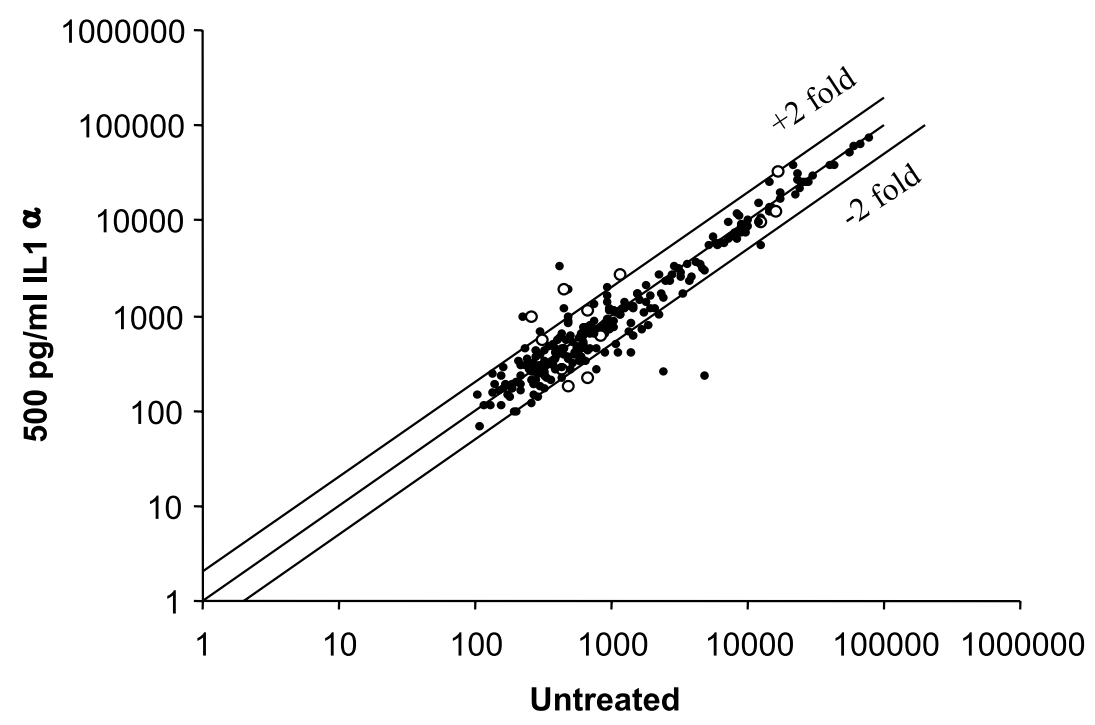

Figure 2 Regression plot of global effects of IL- $1 \alpha$ treatment ( $500 \mathrm{pg} / \mathrm{ml}, 48 \mathrm{~h}$ duration) on primary cultures derived from five separate women (mean of five experiments). Upper line indicates 2 -fold up-regulation, lower line indicates 2 -fold down-regulation, middle line indicates no regulation by IL- $1 \alpha$. Open circles represent genes whose expression profiles were found to be significantly different over the $n=5$ population between untreated and IL-1 $\alpha$-treated cultures.

\section{Steroid-metabolising enzymes}

Relatively abundant expression of many key steroidmetabolising enzymes was apparent, including members of the steroid dehydrogenase/reductase (SDR) gene family responsible for inter-conversion of active and inert congeners of hormonal steroids: $3 \beta$ HSD1, $11 \beta \mathrm{HSD} 1$ and $17 \beta$ HSD types $1,2,4$ and 7 . The testis-specific $17 \beta \mathrm{HSD}$ isoform, $17 \beta \mathrm{HSD} 3$, was not expressed. Steroid $5 \alpha-$ reductase types 1 and 2 were also not expressed above sensitivity threshold levels (although steroid $5 \beta$-reductase was), implying an inability of HOSE cells to produce $5 \alpha$-reduced androgens. Enzymes (CYP11B1 and CYP11B2) required for the metabolism of glucocorticoids to the mineralocorticoid aldosterone were present, as were those involved in the formation and hydrolysis of conjugated sex steroids. These last included steroid sulphatase, which converts oestrone-sulphate into oestrone. Oestrogen sulphotransferase which catalyses the reverse reaction, was not expressed.

\section{Nuclear receptors}

Nuclear receptors for oestrogens (ER $\alpha$ and $\operatorname{ER} \beta$ ), progesterone (PR), glucocorticoids (GR) and androgens (AR) were all present. Other nuclear receptor and related genes expressed by HOSE cells included: retinoic acid receptor (RAR) $\alpha, \operatorname{RAR} \beta 4$ and $\operatorname{RAR} \gamma$; thyroid hormone receptors (TR $\alpha 2$ ); peroxisome-proliferation-activated receptors (PPAR) $\delta$, PPAR $\gamma 2$ and related proteins, PPAR coactivator 1 and PPAR-binding protein (transcription coactivator PBP); heat-shock protein 90 (Hsp90) and a range of orphan nuclear receptors.

\section{Responsiveness to $I L-1 a$}

Of the core genes on the microarray directly involved in steroid signalling, only one (11ßHSD1) was stimulated and another (3 $\beta$ HSD1) inhibited by treatment with IL-1 $\alpha$. A total of 12 genes were significantly affected by treatment with IL-1 $\alpha$ (Fig. 2). The affected genes are listed in Tables 1 and 2, showing positive and negative responders respectively.

\section{Verification by PCR}

RT-PCR was performed to verify that the observed changes in gene expression level, determined by microarray, accurately reflect transcript induction. Using the

Table 1 Genes in cultured HOSE cells up-regulated by treatment with IL- $1 \alpha$, based upon EUROSTERONE custom microarray analysis (mean fold change \pm S.E.M.)

\begin{tabular}{|c|c|c|c|}
\hline & Name & Fold change & $P$ value \\
\hline $\begin{array}{l}\text { Genebank no. } \\
\text { XM031289 }\end{array}$ & Interleukin-8 & $+3 \cdot 72 \pm 0.46$ & $<0 \cdot 01$ \\
\hline M14584 & Interleukin-6 & $+4.93 \pm 1.20$ & $<0.01$ \\
\hline J00271 & Metallothionein-IIA & $+2 \cdot 49 \pm 0.59$ & $<0.05$ \\
\hline M69043 & NFKB inhibitor $\alpha$ & $+2.43 \pm 0.55$ & $<0 \cdot 05$ \\
\hline AH006349 & $11 \beta$ HSD type 1 & $+1 \cdot 83 \pm 0 \cdot 12$ & $0 \cdot 01$ \\
\hline S78694 & Lysyl oxidase & $+2 \cdot 11 \pm 0 \cdot 43$ & $<0.05$ \\
\hline
\end{tabular}


Table 2 Genes in cultured HOSE cells down-regulated by treatment with IL- $1 \alpha$, based upon EUROSTERONE custom microarray analysis (mean fold change \pm S.E.M.)

\begin{tabular}{|c|c|c|c|}
\hline & Name & Fold change & $P$ value \\
\hline $\begin{array}{l}\text { Genebank no. } \\
\text { Y13467 }\end{array}$ & PPARbp & $-1.51 \pm 0.06$ & $0 \cdot 01$ \\
\hline $\mathrm{AH} 005567$ & GnRH receptor & $-1 \cdot 29 \pm 0.06$ & $<0.05$ \\
\hline AF003341 & Aldehyde dehydrogenase 1 soluble & $-2 \cdot 60 \pm 0.09$ & $<0.05$ \\
\hline S45679 & $3 \beta \mathrm{HSD} 1$ & $-2 \cdot 17 \pm 0 \cdot 12$ & $<0.05$ \\
\hline M64497 & $\begin{array}{l}\text { Nuclear receptor subfamily } 2 \\
\text { group } \mathrm{F} \text { member } 2 \text { (COUP-TF II) }\end{array}$ & $-1 \cdot 36 \pm 0 \cdot 08$ & $<0.05$ \\
\hline 147162 & Aldehyde dehydrogenase 10 & $-1 \cdot 24 \pm 0.06$ & $<0.05$ \\
\hline
\end{tabular}

same RNA preparation used for microarray analysis, gene-specific PCR was performed on a selection $(n=7)$ of the genes modulated by IL-1 $\alpha$.

This analysis confirmed the reliability of the microarray data: all the genes tested showed the predicted shifts in expression, and to a generally comparable degree (Table 3).

\section{Responsiveness to glucocorticoid}

Non-steroidogenic genes induced by IL-1 $\alpha$ were deemed by definition to be 'inflammatory' and therefore were predicted to be responsive to cortisol, the metabolic product of $11 \beta$ HSD 1 . This hypothesis was tested on LOX (an enzyme crucial to the deposition of mature collagen and elastin), showing reversal of IL- $1 \alpha$-stimulated LOX mRNA by cortisol in HOSE cell cultures from three out of three patients (Fig. 3).

\section{Discussion}

We demonstrate that cultured HOSE cells express all the genes required to synthesise de novo steroids in the C21pregnane and C19-androstane series. They also express steroid dehydrogenase, hydroxylase and conjugation/ deconjugation enzymes that endow the capacity to reversibly activate or inactivate multiple steroidal substrates. Critically, however, they lack detectable CYP19, necessary for androgen aromatisation to oestrogen, and CYP21, required for C-21 hydroxylation and production of glucocorticoids.

This custom microarray analysis powerfully reinforces previous reports that human (Rembiszewska \& Brynczak 1985) and sheep (Murdoch et al. 1999) OSE cells have limited steroid biosynthetic potential. It was not feasible to verify this conclusion exhaustively at the metabolic level. However, consistent with absence of CYP19 and presence of $11 \beta$ HSD1 gene expression defined by the microarray, we confirmed absence of measurable aromatase enzyme activity (data not shown) but presence of 11-oxoreductase (Yong et al. 2002) in cultured HOSE cells. This, combined with the verification of selected genes by quantitative RT-PCR (Table 3), provides a strong measure of confidence in the validity of the present microarray dataset.

Exposure of HOSE cells to IL-1 $\alpha$, as a surrogate inflammatory stimulus, was expected to cause pronounced changes in the steroidogenic expression profile of HOSE cells. In agreement with our previous finding (Yong et al. 2002), 11ßHSD1 was stimulated by the cytokine. However, only one other steroidogenic gene was affected: $3 \beta$ HSD1, which was suppressed. $3 \beta$ HSD1 plays a critical role in steroid interconversion through catalysing the formation of 'mature' $\Delta^{4}-3$-oxo-C21 and -C19 products (progesterone, androstenedione) from immediate $\Delta^{5}-3-$ hydroxy precursors (pregnenolone, dehydroepiandrosterone). Thus, at least during exposure to inflammation such

Table 3 Subset of IL-1 $\alpha$-regulated genes randomly selected and validated by quantitative real-time PCR on the same samples subjected to microarray analysis (mean fold change \pm S.E.M.)

\begin{tabular}{|c|c|c|c|}
\hline & Name & Fold change & $P$ value \\
\hline $\begin{array}{l}\text { Genebank no. } \\
\text { M14584 }\end{array}$ & Interleukin-6 & $+20 \cdot 93 \pm 10 \cdot 66$ & $<0 \cdot 05$ \\
\hline M69043 & NFKB inhibitor $\alpha$ & $+4.61 \pm 0.98$ & $<0.05$ \\
\hline AH006349 & $11 \beta \mathrm{HSD}$ type 1 & $+12 \cdot 94 \pm 3 \cdot 89$ & $<0 \cdot 01$ \\
\hline S78694 & Lysyl oxidase & $+3 \cdot 18 \pm 0 \cdot 31$ & $<0 \cdot 01$ \\
\hline Y13467 & PPARbp & $-1 \cdot 35 \pm 0 \cdot 13$ & $<0.05$ \\
\hline AF003341 & Aldehyde dehydrogenase 1 soluble & $-4 \cdot 74 \pm 0.53$ & $<0 \cdot 01$ \\
\hline S45679 & $3 \beta \mathrm{HSD} 1$ & $-4 \cdot 28 \pm 0 \cdot 37$ & $<0 \cdot 01$ \\
\hline
\end{tabular}




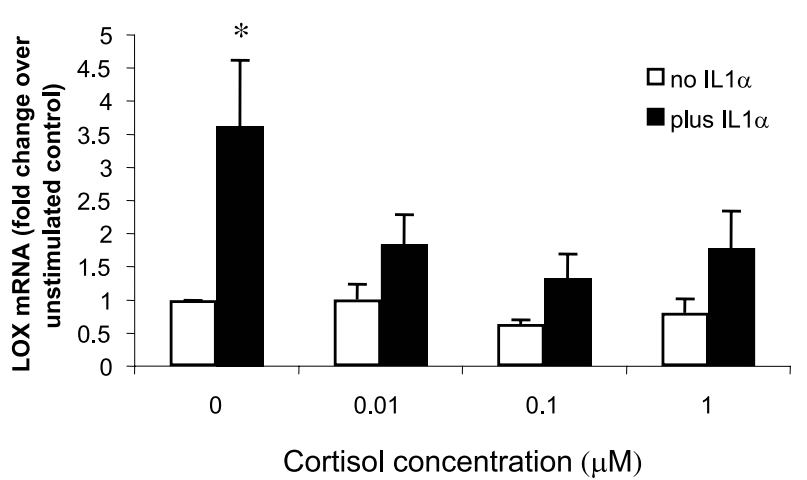

Figure 3 Glucocorticoid-suppression of IL- $1 \alpha$-induced LOX mRNA expression in cultured HOSE cells. Real-time PCR was used to determine gene expression changes due to IL- $1 \alpha$ and cortisol in primary HOSE cultures derived from three women. IL-1 $\alpha$ significantly increased expression of LOX mRNA $(P<0 \cdot 05)$. Cortisol alone had no effects; however, at all doses tested, it prevented the stimulatory effects of IL- $1 \alpha(P<0 \cdot 05$ as compared with IL- $1 \alpha$ alone). ${ }^{*}$ Significant difference, $P<0 \cdot 05$.

as encountered during ovulation, the HOSE is likely to function less as a de novo steroid hormone-producing tissue than one of steroid transformation.

$11 \beta H S D 1$ and 3 3 HSD 1 are members of the SDR gene family, which encode enzymes that reversibly metabolise lipid-signalling molecules such as steroids, retinoids and prostaglandins (Oppermann 2001). Other SDR probes in the microarray included ALDH10 and ALDH1 soluble, both of which were expressed in HOSE cells and downregulated by treatment with IL-1 $\alpha$. ALDH isoforms constitute a large family of enzymes with the general reaction of catalysis of oxidation of long-chain aliphatic aldehydes to fatty acids, but may also act on steroidal substrates. For instance, yeast SDRs FOX2 and AYR1 are active on long- and short-chain (3R)-hydroxyacyl-CoA substrates (Qin et al. 1999) and 1-acyl dihydroxyacetone phosphate (Athenstaedt \& Daum 2000) respectively, but display surprisingly robust $17 \beta \mathrm{HSD}$ activity on dehydroepiandrosterone (DHEA)/androstenediol (Vico et al. 2002); some long-chain fatty acyl substrates may fold to adopt a steroid-like configuration on enzyme binding. The function of ALDHs also include reversible oxidation/reduction of retinol and retinal (Duester 2000), providing a mechanism for gating access of these ligands to RAR's. We found RAR $\alpha, \operatorname{RAR} \beta 4$ and $\operatorname{RAR} \gamma$ genes expressed in HOSE cells, underscoring the likelihood that ligandactivated RAR signalling is important to their development and survival in vivo ( $\mathrm{Um}$ et al. 2001).

The presence of GR supports our central hypothesis that glucocorticoid fulfils anti-inflammatory signalling functions in the HOSE (Rae et al. 2004). This last study used quantitative RT-PCR to distinguish weak upregulation of GR $\alpha$ mRNA by IL- $1 \alpha$, which was not resolved by the microarray analysis used here, presumably due to its relative insensitivity.
The expression of PPAR $\delta$, PPAR $\gamma 2$, PPAR coactivator 1 and PPAR-binding protein, and downregulation of PPARbp by IL-1 $\alpha$, is of special interest in view of the inferred overlaps between glucocorticoid and PPAR signalling (e.g. Lemberger et al. 1996, Johnson et al. 1999). However, many studies addressing PPAR function have depended on the thiazolidinedione (TZD) group of drugs such as effectors; this area may need to be reinterpreted in the light of a recent suggestion that TZDs primarily target a mitochondrial protein (Colca et al. 2004). PPARbp (also PBP) was identified as a coactivator for PPAR $\gamma$ but also binds to PPAR $\alpha, \operatorname{RAR} \alpha, \operatorname{RXR}$ and TP $\beta 1$ (Zhu et al. 1997), and a role in thyroid hormone signalling has been emphasised (Misra et al. 2002). In addition, over-expression of PPARbp has been reported in one-quarter of breast cancers examined, indicating a role in mammary epithelial differentiation and cancer development (Zhu et al. 1999) that may translate to the ovary. Suppression of PPARbp by IL-1 $\alpha$ is novel, and possibly mediated via nuclear factor $\kappa \mathrm{B}(\mathrm{NF \kappa B})$, since there is a putative binding site for $\mathrm{NFKB}$ on the PPARbp gene (Zhu et al. 1999).

The presence of $\mathrm{ER} \alpha$ and $\beta, \mathrm{AR}$ and $\mathrm{PR}$ confirms HOSE cells as sex-steroid targets, underscored by the detection of Hsp90, a molecular chaperone with an established function in the stabilisation of non-liganded nuclear receptors (Cadepond et al. 1991). The relative importance of $\mathrm{ER} \alpha$ and $\mathrm{ER} \beta$ in mediating cytoproliferative and other effects of oestrogen on HOSE cells is unknown but both are expressed (Hillier et al. 1998, Li et al. 2003). Notably, although steroid sulphatase was expressed, oestrone sulphotransferase was not. Thus HOSE cells may be exposed to locally enhanced levels of oestrogen by activation from oestrone sulphate, which circulates as the most abundant oestrogen in blood (Loriaux et al. 1971). Onward metabolism of oestrone to oestradiol is also predicted by the pattern of $17 \beta \mathrm{HSD}$ isoforms expressed. In support of this suggestion, in studies examining the role of oestrogens in normal OSE and malignant OSE cells, oestrone was found to be as effective as oestradiol in promoting cell proliferation (Syed et al. 2001); data presented here may explain this finding. The presence of AR in HOSE is in agreement with the pro-proliferative/ anti-apoptotic effect of androgen on a virally transformed HOSE cell line reported by Edmondson et al. (2002). The presence of PR agrees with the anti-proliferative (Karlan et al. 1995, Murdoch \& Van Kirk 2002) and antiinflammatory (Rae et al. 2004) effects of progesterone that others have described. Additionally, we note expression of the membrane-bound progesterone receptor, providing a potential alternative route of progesterone action on these cells.

Other nuclear receptors expressed in HOSE cells include oestrogen-related receptors (ERR) $\alpha$ and ERR $\beta$, which share a DNA-binding domain with $\mathrm{ER} \alpha$ but are not activated by classical oestrogens. Their function in 
HOSE cells is yet to be defined but, at least for ERR $\alpha$, a role in fatty acid metabolism is possible (Sladek et al. 1997). HOSE cells also express TR $\alpha 2$ and TR $\beta$. To our knowledge, no published reports exist of thyroid hormone action on HOSE cells. However, epidemiological links between development of ovarian cancer, inflammation of the ovarian surface and hyperthyroidism have been previously established (Ness et al. 2000). In rats, direct action of thyroid hormones on the ovary has been discussed (Horii et al. 1992); studies in women have pointed to thyroid insufficiency as a possible cause of infertility (Gerhard et al. 1991, Raber et al. 2003). Further studies to elucidate the signalling function of thyroid hormone in normal and diseased HOSE cells are therefore urgently required.

Two genes in the array other than $3 \beta$ HSD1, ALD1 soluble, ALD 10 and PPARbp were significantly down-regulated by IL-1 $\alpha$ treatment. Expression of gonadotrophin-releasing hormone receptor (GnRH-R) has previously been demonstrated in HOSE cells, for which $\mathrm{GnRH}$ is anti-proliferative in vitro (Kang et al. 2000). The functional significance of its suppression by IL-1 $\alpha$ remains unknown. The orphan steroid/retinoid receptor nuclear receptor subfamily 2 group $\mathrm{F}$ member 2 (also known as chicken ovalbumin upstream promoter transcription factor II-COUP TF II) was also downregulated by treatment with IL-1 $1 \alpha$. We are unaware of any previous report of this gene being expressed in the ovary. Its spatiotemporal expression pattern during mouse development suggests involvement in angiogenesis (Pereira et al. 1999). Such a role could be relevant to post-ovulatory tissue remodelling in the ovary. Importantly, it has been suggested that this gene may be a potential therapeutic target in disease conditions such as cancer where aberrant angiogenesis is a hallmark of disease progression (Pereira et al. 1999).

Treatment with IL-1 $\alpha$ stimulated the expression of five non-steroidogenic genes in the array, other than 11ßHSD1: metallothionein-IIA (MT-IIA), previously implicated in protection against the oxidative stress generated by the inflammation associated with ovulation (Espey et al. 2003); IL-6 and IL-8, established components of the ovulation-associated inflammatory cascade; LOX, responsible for the final catalysis of collagen formation and hence ECM deposition (Harlow et al. 2003); and NFK $\beta$ inhibitor $\alpha$, expression of which is associated as a downstream consequence of $N F \kappa \beta$ signalling, which is in turn associated with inflammatory signalling. It has not escaped our attention that all these IL-1 $\alpha$-responsive genes are potentially regulated by glucocorticoids in HOSE cells. Thus, cortisol dose-dependently enhances IL-1 $\alpha-$ stimulated $11 \beta$ HSD1 expression in HOSE cells (Rae et al. 2004); tumour-necrosis factor- $\alpha$ (TNF $\alpha$ )-induced expression of IL-8 and Il-6 mRNA in human fibroblasts is suppressed by dexamethasone (Tobler et al. 1992); MT-IIA possesses a GR response element and is inducible by glucocorticoids (Karin et al. 1984); LOX enzyme activity in rat skin is inhibited by glucocorticoids (Counts et al. 1986), and as shown here, cortisol suppresses IL-1 $\alpha-$ induced LOX mRNA expression in HOSE cells. This leads us to suggest that induction by IL-1 $\alpha$ of $11 \beta$ HSD1, augmented by cortisol, might serve to generate the glucocorticoid required to induce/repress anti-/proinflammatory gene responses in vivo (Rae et al. 2004). Moreover, through augmenting IL-1 $\alpha$-stimulated $11 \beta$ HSD1 activity, cortisol would sustain its own regeneration and thereby amplify GR-mediated antiinflammatory signalling in the postovulatory HOSE (Rae et al. 2004). However, although cortisone is the classic $11 \beta \mathrm{HSD} 1$ substrate, we cannot rule out the possibility that other substrates for this enzyme are present in HOSE cells.

Caveats to this study are that we have provided a restricted gene expression profile for cultured cells at a fixed time of stimulation. Concerning the first point, the central weakness of microarray studies is that the significance of individual levels of gene expression cannot easily be addressed, nor is it possible to ascertain whether mRNA levels accurately reflect polypeptide expression. However, we feel that induced changes in gene expression levels such as those observed here, and confirmed by PCR, are likely to reflect changes in polypeptide product levels irrespective of translational efficiency. Further, the core gene set comprehensively covered the conventional steroid biosynthetic pathway module, which was the main purpose of the exercise. We duly acknowledge that sensitivity of microarray may permit false-negative data, i.e. apparent lack of expression of a gene, as compared with metabolic profiling. However, as a site of major endocrine-related gynaecological disease - including ovarian cancer and endometriosis - there is an urgent need to catalogue, characterise and comprehend the expression profile of genes in HOSE cells involved in steroid signalling, in order to define new diagnostic and therapeutic targets. Regarding the second point, the only way that sufficient HOSE cells for array analysis can be obtained from individual patients is to biopsy and propagate in vitro, as described here. The extent to which HOSE cells propagated for 3 weeks in vitro reflect an in vivo phenotype is difficult to assess. However, a benefit of primary culture is that any confounding patient-to-patient variable should have been minimised, as suggested by the remarkably uniform response to IL- $1 \alpha$ given by the cells from all five patients. A strength of this study is that it compared 'like with like', that is, all samples were primary cell cultures, and each had an untreated and a treated component, identical to each other in all other ways. Selection of a suitable control in gene profiling studies in HOSE has recently been shown to dramatically effect data and interpretation (Zorn et al. 2003). Thirdly, the use of a $48 \mathrm{~h}$ period of stimulation by fixed-dose IL- $1 \alpha$ was a compromise, based on previous evidence that $11 \beta \mathrm{HSD} 1 \mathrm{mRNA}$ and enzyme activity in HOSE cells are maximally stimulated under these conditions. (Yong et al. 2002, Rae et al. 
2004). The trade-off for this restriction could be that earlier gene changes might have been missed. These criticisms aside, the dataset presented provides novel and revealing information on this poorly understood specialised human ovarian cell type.

In conclusion, we have used a custom oligonucleotide microarray to define the steroidogenic potential of cultured HOSE cells and investigate changes associated with inflammatory stimulation through exposure to IL-1 $\alpha$. Results suggest that the HOSE is principally a site of steroid metabolism and reception as opposed to de novo steroid hormone synthesis. Intriguingly, the only steroidogenic gene detectably up-regulated by IL-1 $\alpha$ is $11 \beta$ HSD1. Non-steroidogenic genes affected include pro-/anti-inflammatory genes whose expression is inhibited/augmented by corticosteroid. Since the steroidogenic function of $11 \beta \mathrm{HSD} 1$ is to regenerate cortisol from cortisone, these results support the hypothesis that locally produced glucocorticoids play significant roles in HOSE cell function, including a possible anti-inflammatory action around the time of ovulation.

\section{Note added in proof}

During preparation of this article for publication, COUP-TF II has been found to be downregulated in ovarian cancer cells (Lee et al. 2004).

\section{Acknowledgements}

We thank Klemens Vierlanger for probe design, Douglas Roy for his management of the EUROSTERONE microarray project, Joe Gaughan of Qiagen Ltd for his advice on resonance light scatter detection techniques, and Professor J I Mason for helpful discussion on steroid metabolism. We also wish to acknowledge Dr Alex Bailey for coordination of the EUROSTERONE Network.

\section{Funding}

Supported by the European Commission (QLRI-CT1999-00762), the Medical Research Council (Programme grant 0000066) and Scottish Higher Education Council research and development award, BBSRC. None of the authors declare a conflict of interest that would prejedice the impartiality of this research.

\section{References}

Athenstaedt K \& Daum G 2000 1-Acyldihydroxyacetone-phosphate reductase (Ayr1p) of the yeast Saccharomyces cerevisiae encoded by the open reading frame YIL124w is a major component of lipid particles. Journal of Biological Chemistry 275 235-240.
Auersperg N, Wong AST, Choi KC, Kang SK \& Leung PCK 2001 Ovarian surface epithelium: biology, endocrinology and pathology. Endocrine Reviews 22 255-288.

Cadepond F, Schweizer-Groyer G, Segard-Maurel I, Jibard N, Hollenberg SM, Giguere V, Evans RM \& Baulieu EE 1991 Heat shock protein 90 as a critical factor in maintaining glucocorticosteroid receptor in a nonfunctional state. Journal of Biological Chemistry 266 5834-5841.

Colca JR, McDonald WG, Waldon DJ, Leone JW, Lull JM, Bannow CA, Lund ET \& Mathews WR 2004 Identification of a novel mitochondrial protein ('mitoNEET') cross-linked specifically by a thiazolidinedione photoprobe. American Journal of Physiology Endocrinology and Metabolism 286 E252-E260.

Counts DF, Shull S \& Cutroneo KR 1986 Skin lysyl oxidase activity is not rate limiting for collagen crosslinking in the glucocorticoid-treated rat. Connective Tissue Research 14 237-243.

Duester G 2000 Families of retinoid dehydrogenases regulating vitamin A function: production of visual pigment and retinoic acid. European Journal of Biochemistry 267 4315-4324.

Edmondson RJ, Monaghan JM \& Davies BR 2002 The human ovarian surface epithelium is an androgen responsive tissue. British Journal of Cancer 86 879-885.

Espey LL, Ujioka T, Okamura H \& Richards JS 2003 Metallothionein-1 messenger RNA transcription in steroid-secreting cells of the rat ovary during the periovulatory period. Biology of Reproduction 68 1895-1902.

Forster T, Roy D \& Ghazal P 2003 Experiments using microarray technology: limitations and standard operating procedures. Journal of Endocrinology 78 195-204.

Gerhard I, Eggert-Kruse W, Merzoug K, Klinga K \& Runnebaum B 1991 Thyrotropin-releasing hormone (TRH) and metoclopramide testing in infertile women. Gynecological Endocrinology 5 15-32.

Harlow CR, Rae M, Davidson L, Trackman PC \& Hillier SG 2003 Lysyl oxidase gene expression and enzyme activity in the rat ovary: regulation by follicle-stimulating hormone, androgen, and transforming growth factor-beta superfamily members in vitro. Endocrinology 144 154-162.

Hillier SG 2003 Steroids in health and disease (Eurosterone) QLRI-CT-1999-00762. In Generic RTD activities and research infrastructures FP5 1998-2002, pp 491-492. Ed SS Baig. Brussels: European Commission.

Hillier SG, Anderson RA, Williams AR \& Tetsuka M 1998 Expression of oestrogen receptor alpha and beta in cultured human ovarian surface epithelial cells. Molecular Human Reproduction $\mathbf{4}$ 811-815.

Hillier SG \& Tetsuka M 1998 An anti-inflammatory role for glucocorticoids in the ovaries? Journal of Reproductive Immunology 39 21-27.

Horii I, Takizawa S \& Fujii T 1992 Effect of 1,25-dihydroxyvitamin D3 on the female reproductive system in rats. Journal of Toxicology Science 17 91-105.

Johnson TE, Vogel R, Rutledge SJ, Rodan G \& Schmidt A. 1999 Thiazolidinedione effects on glucocorticoid receptor-mediated gene transcription and differentiation in osteoblastic cells. Endocrinology 140 3245-3254.

Kang SK, Choi K, Cheng KW, Nathwani PS, Auersperg N \& Leung PC 2000 Role of gonadotrophin releasing hormone as an autocrine growth factor in human OSE. Endocrinology 141 72-80.

Karin M, Haslinger A, Holtgreve H, Richards RI, Krauter P, Westphal HM \& Beato M 1984 Characterization of DNA sequences through which cadmium and glucocorticoid hormones induce human metallothionein-IIA gene. Nature 308 513-519.

Karlan BY, Jones J, Greenwald M \& Lagasse LD 1995 Steroid hormone effects on the proliferation of human ovarian surface epithelium in vitro. American Journal of Obstetrics and Gynecology 173 97-104. 
Lau KM, Mok SC \& Ho SM 1999 Expression of human estrogen receptor-alpha and -beta, progesterone receptor, and androgen receptor mRNA in normal and malignant ovarian epithelial cells. PNAS 96 5722-5727.

Lee BC, Cha K, Avraham S \& Avraham HK 2004 Microarray analysis of differentially expressed genes associated with human ovarian cancer. International Journal of Oncology 24 847-851.

Lemberger T, Saladin R, Vazquez M, Assimacopoulos F, Staels B, Desvergne B, Wahli W, Auwerx J, Burger AG, Meier CA \& Wahli W 1996 Expression of the peroxisome proliferator-activated receptor alpha gene is stimulated by stress and follows a diurnal rhythm. Journal of Biological Chemistry 271 1764-1769.

Li AJ, Baldwin RL \& Karlan BY 2003 Estrogen and progesterone receptor subtype expression in normal and malignant ovarian epithelial cell cultures. American Journal of Obstetrics and Gynecology $18922-27$.

Loriaux DL, Ruder HJ \& Lipsett MB 1971 The measurement of estrone sulfate in plasma. Steroids 18 463-724.

Misra P, Owuor ED, Li W, Yu S, Qi C, Meyer K, Zhu YJ, Rao MS, Kong AN \& Reddy JK. 2002 Phosphorylation of transcriptional coactivator peroxisome proliferator-activated receptor (PPAR)-binding protein (PBP). Stimulation of transcriptional regulation by mitogen-activated protein kinase. Journal of Biological Chemistry 277 48745-48754.

Murdoch WJ \& Van Kirk EA 2002 Steroid hormonal regulation of proliferative, p53 tumor suppressor, and apoptotic responses of sheep ovarian surface epithelial cells. Molecular and Cellular Endocrinology 186 61-67.

Ness RB, Grisso JA, Cottreau C, Klapper J, Vergona R, Wheeler JE, Morgan M \& Schlesselman JJ 2000 Factors related to inflammation of the ovarian epithelium and risk of ovarian cancer. Epidemiology 11 111-117.

Oppermann UC, Filling C \& Jornvall H 2001 Forms and functions of human SDR enzymes. Chemico-Biological Interactions 30 699-705.

Pereira FA, Qui Y, Zhou G, Tsai M-J \& Tsai SY 1999 The orphan nuclear receptor COUP-TFII is required for angiogenesis and heart development. Genes and Development 13 1037-1049.

Qin YM, Marttila MS, Haapalainen AM, Siivari KM, Glumoff T \& Hiltunen JK 1999 Yeast peroxisomal multifunctional enzyme: (3R)-hydroxyacyl-CoA dehydrogenase domains A and B are required for optimal growth on oleic acid. Journal of Biological Chemistry $27428619-28625$.

Raber W, Nowotny P, Vytiska-Binstorfer E \& Vierhapper H 2003 Thyroxine treatment modified in infertile women according to thyroxine-releasing hormone testing: 5 year follow-up of 283 women referred after exclusion of absolute causes of infertility. Human Reproduction 18 707-714.
Rae MT, Niven D, Critchley HOD, Harlow CR \& Hillier SG 2004 Anti-inflammatory steroid action in human ovarian surface epithelial cells. Journal of Clinical Endocrinology and Metabolism (In Press).

Rembiszewska A \& Brynczak A 1985 Steroidogenic activity in surface epithelium of the human ovary. Folia Histochemica et Cytobiologica 23 159-163.

Sladek R, Bader JA \& Giguere V 1997 The orphan nuclear receptor estrogen-related receptor alpha is a transcriptional regulator of the human medium-chain acyl coenzyme A dehydrogenase gene. Molecular and Cellular Biology 17 5400-5409.

Syed V, Ulinski G, Mok SC, Yiu GK \& Ho S-K 2001 Expression of gonadotropin receptor and growth responses to key reproductive hormones in normal and malignant ovarian surface epithelial cells. Cancer Research 61 6768-6776.

Tobler A, Meier R, Seitz M, Dewald B, Baggiolini M \& Fey MF 1992 Glucocorticoids downregulate gene expression of GM-CSF, NAP-1/IL-8 and IL-6, but not of M-CSF in human fibroblasts. Blood 79 45-51.

Um SJ, Lee SY, Kim EJ, Han HS, Koh YM, Hong KJ, Sin HS \& Park JS 2001 Antiproliferative mechanism of retinoid derivatives in ovarian cancer cells. Cancer Letters 174 127-134.

Vico P, Cauet G, Rose K, Lathe R \& Degryse E 2002 Dehydroepiandrosterone (DHEA) metabolism in Saccharomyces cerevisiae expressing mammalian steroid hydroxylase CYP7B: Ayr1p and Fox $2 \mathrm{p}$ display 17 beta-hydroxysteroid dehydrogenase activity. Yeast 19 873-886.

Yong PY, Harlow C, Thong KJ \& Hillier SG 2002 Regulation of 11 beta-hydroxysteroid dehydrogenase type 1 gene expression in human ovarian surface epithelial cells by interleukin-1. Human Reproduction 17 2300-2306

Zhu Y, Qi C, Jain S, Rao MS \& Reddy JK 1997 Isolation and characterization of $\mathrm{PBP}$, a protein that interacts with peroxisome proliferator-activated receptor. Journal of Biological Chemistry 272 25500-25506

Zhu Y, Qi C, Jain S, Le Beau MM, Espinosa R 3rd, Atkins GB, Lazar MA, Yeldandi AV, Rao MS, Reddy JK 1999 Amplification and overexpression of peroxisome proliferator-activated receptor binding protein (PBP/PPARBP) gene in breast cancer. PNAS 96 10848-10853.

Zorn KK, Jazaeri AA, Awtrey CS, Gardner GJ, Mok SC, Boyd J \& Birrer MJ 2003 Choice of normal ovarian control influences determination of differentially expressed genes in ovarian cancer expression profiling studies. Clinical Cancer Research 9 4811-4818.

Received 17 March 2004

Accepted 9 June 2004 